\title{
Erratum
}

\section{Erratum: Liang et al., The stat3/socs $3 a$ Pathway Is a Key Regulator of Hair Cell Regeneration in Zebrafish}

In the article "The stat3/socs3a Pathway Is a Key Regulator of Hair Cell Regeneration in Zebrafish stat3/socs3a Pathway: Regulator of Hair Cell Regeneration” by Jin Liang, Dongmei Wang, Gabriel Renaud, Tyra G. Wolfsberg, Alexander F. Wilson, and Shawn M. Burgess, which appeared on pages 10662-10673 of the August 1, 2012 issue, the Running Title was incorrectly added as part of the Article Title. The correct Article Title is as follows: The stat3/socs3a Pathway Is a Key Regulator of Hair Cell Regeneration in Zebrafish. The Article Title has been corrected on the online PDF version.

DOI: 10.1523/JNEUROSCI.3956-12.2012 